\title{
Influence of Rotational Speed in the Friction Surfacing of Titanium Grade 1 on Ti-6Al-4V
}

\author{
Natália Lopes do Vale ${ }^{a *}$,Viktoria Fitseva ${ }^{b}$, Stefanie Hanke ${ }^{b}$, Severino Leopoldino Urtiga Filho ${ }^{a}$, \\ Jorge Fernandez dos Santos ${ }^{b}$ \\ ${ }^{a}$ Programa de Pós-Graduação em Engenharia Mecânica, Universidade Federal de Pernambuco, Recife, \\ PE, Brazil \\ ${ }^{b}$ Helmholtz-Zentrum Geesthacht GmbH, Institute of Materials Research, Materials Mechanics, Solid \\ State Joining Processes (WMP), Germany
}

Received: December 12, 2016; Revised: November 16, 2017; Accepted: December 14, 2017

\begin{abstract}
Titanium Grade 1 was deposited on Ti-6Al-4V, 2 mm thickness, by Friction Surfacing. The process parameters were rotational speed, deposition speed and consumption rate. Only the rotational speed was varied in order to evaluate the influence of this parameter on the coatings generated. The applicability of the process has been described for a large number of materials, although the depositions of titanium alloys are still not widely studied. The objective is to investigate the effects of the rotational speed on the coatings' geometry and microstructural evolution. This investigation has shown that Titanium Grade 1 coatings can be deposited onto a Ti-6Al-4V by Friction Surfacing depending on the rotational speed. The coatings' surface homogeneity was influenced by the rotational speed, being inhomogeneous for the lowest speed. The coatings' thickness and width increased with enhancing this speed. The heat affected zone in the substrate corresponded to the complete thickness under the depositions.
\end{abstract}

Keywords: Friction Surfacing, Titanium, Coating Geometry, Microstructure.

\section{Introduction}

The Friction Surfacing (FS) technique has become an essential form of surface engineering, since the coatings deposited by this process may be used for extending the service life of various components by repairing worn parts and improving wear resistance and anticorrosion properties ${ }^{1,2}$.

The FS concept was first patented as a metal coating process by Klopstock and Neelands, in $1941^{3}$. Although FS remained relatively dormant in the following decades, since the late 80 s the process has been studied more frequently and used in the manufacturing industry ${ }^{4}$. The FS process is based on the plastic deformation of a rotating metallic consumable rod, which is pressed against the substrate material under an applied axial load. Frictional heat is then generated at the interface between the rod and the substrate due to its relative motion, resulting in a layer of plasticized material, which is deposited as a coating without the need for an external heat source. The pressure and temperature conditions that results from the process are responsible for the bonding between the plasticized material and the substrate ${ }^{5}$. Therefore, this technique is considered as a solid state process, since the coatings are generated at temperatures below the melting range of the materials. A schematic presentation of the FS process is shown in Figure 1. The main process parameters are the rotational speed of the consumable rod, the deposition speed and the consumption rate.

*e-mail: natalia.dovale@hotmail.com
During the process it is generated a revolving flash of plasticized material, which generally ascends around the consumable rod, leaving the coating without flash. Flash formation is due to a portion of plasticized material that is pushed by the axial force out of the contact zone between the rod and substrate, giving it a characteristic mushroomshaped geometry ${ }^{4,7}$. The maximum length of the coating is determined by the rod length. Therefore, the coating length may be reduced by the amount of material being lost to the formation of flash. Another common feature in the FS technique is a lack of bonding in a narrow region along both edges of the coating, which in the literature is frequently called "undercut"8,9,10. This undercut phenomenon is due to the fact that the plasticized, i.e. thermally softened, material at the outer edge of the rod is not able to carry the axial force applied. The advancing side (AS) is the edge at which the direction of the rotational speed is the same as the deposition direction and, on the contrary, the retreating side (RS) is the edge where they are in opposite directions ${ }^{1,11,12}$.

During the deposition by FS the original microstructure of the consumable rod is altered by the severe plastic deformation and the thermal cycle that are imposed by the process. Therefore, a recrystallization and refinement of the grains and, depending on the material that is processed, phase transitions take place ${ }^{1,13}$. Compared to conventional welding processes, based on fusion, there is a limited impact on the substrate's microstructure, as a consequence of the comparably low heat input ${ }^{1}$. The process is also known for 


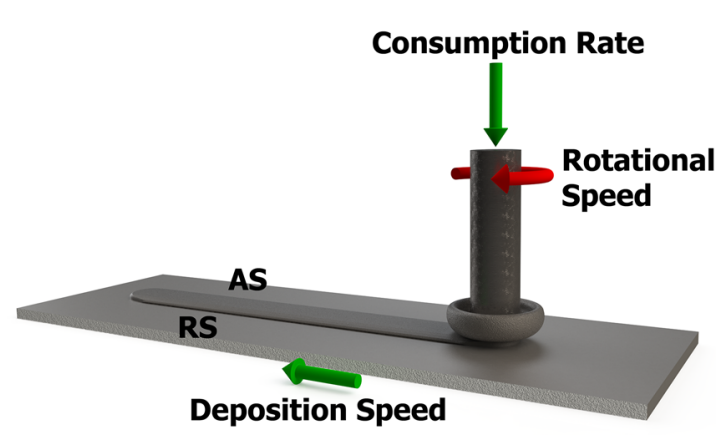

Figure 1. Schematic presentation of FS process ${ }^{6}$

enabling the joining of dissimilar materials, while being able to reduce the distortion of the substrate and the loss of material properties ${ }^{2,14}$. The solid-state adhesion between the coating and the substrate for dissimilar coatings is possible due to the generation of high contact stress and intimate contact between the coating material and substrate ${ }^{15}$. The coatings deposited by FS present many advantages similar to other solid state friction based technologies, including environmental friendliness and avoidance of metallurgical defects inherent to fusion based processes.

Many studies have been published regarding the deposition of different materials by FS, however the majority is related to the deposition of steel and aluminium alloys ${ }^{14,15,16,17}$. The deposition of commercially pure titanium was studied by Rao et $\mathrm{al}^{17}$ but for the conditions applied it could not be deposited on any substrate material selected, even over a Ti-6Al-4V substrate. The feasibility and properties of Ti-6Al$4 \mathrm{~V}$ coatings on self-mating substrate has been shown just recently ${ }^{1}$ and the results were successful. Though titanium is a relatively expensive material, it has interesting properties, such as high strength, low density (approximately $60 \%$ of the density of iron) and good corrosion resistance. Further, the deposition of titanium can be used in a wide range of applications, as in the aircraft industry, for medical implants and other high-performance applications.

The main objective of the present investigation is to demonstrate that Titanium Grade 1 can be deposited onto a Ti-6Al-4V substrate by FS due to its potential use in manufacturing industries, especially for improving corrosion properties. This study addresses the influence of the rotational speed on the coating's geometry and the microstructure generated, since this parameter has a considerable influence on the amount of plasticized material and consequently on the heat input.

\section{Experimental details}

The materials used in this study were Ti-6Al-4V hotrolled plates with dimensions of $300 \mathrm{~mm} \times 100 \mathrm{~mm} \times 2 \mathrm{~mm}$ as substrate for the depositions, and Titanium Grade 1 for the coatings. The latter is unalloyed titanium, and was used as the consumable rod in a rolled condition with a diameter of 20 $\mathrm{mm}$ and $15 \mathrm{~cm}$ length approximately. Chemical composition of both materials as provided by the supplier are shown in Table 1. Substrate surfaces were cleaned with acetone prior to deposition and two coatings were generated on each plate.

The FS was performed using custom-built friction welding equipment, which is capable of delivering $8 \mathrm{kN}$ axial force and $60 \mathrm{Nm}$ of torque through an electrically driven spindle. The rods were fed into the process zone at a constant axial speed, i.e. the process was carried out in consumption rate control mode. The machine is equipped with sensors for the forces in three directions and with a torque sensor implemented in the spindle. Therefore, operating conditions such as axial force, torque, consumable rod consumption, position and deposition speed were monitored in real time with a system attached. Coatings were produced using 1.8 $\mathrm{mm} / \mathrm{s}$ rod consumption rate, $16 \mathrm{~mm} / \mathrm{s}$ deposition speed, and three values of rotational speed: 2000, 3000 and 4000 rpm. Each trial was set to consume a rod length enough to deposit a $130 \mathrm{~mm}$ coating. No shielding gas was used in these experiments.

To analyze the coating features, cross sections of the deposits have been prepared according to standard metallographic procedures (ASTM E3-01 ${ }^{18}$ ). After grinding and polishing, etching was performed using Kroll reagent to reveal the microstructure. Optical microscope (OM) and Laser microscope (LM) were used to evaluate the coating geometry and the microstructural features along the interface. OM was performed using a Leica Microsystems DM IRM, which is an inverted geometry optical microscope. The LM used was a Keyence VK-9700 equipped with the software VK-Analyzer. Image processing techniques allowed measuring the coating cross section area, thickness, width and characterizing the unbonded regions.

\section{Results and Discussion}

\subsection{Coating Appearance}

A typical appearance of the Titanium Grade 1 deposit is shown in Figure 2. The coating surface displays regularly-

Table 1. Chemical composition provided by supplier in weight- $\%$

\begin{tabular}{ccccccccccc}
\hline & Material & Fe & C & N & H & O & Al & V & Ti \\
\hline Consumable rod & Ti Gr 1 & 0.28 & 0.01 & 0.0047 & 0.0011 & 0.089 & 0.26 & 0.03 & Bal. \\
Substrate & Ti-6Al-4V & 0.11 & 0.02 & 0.007 & 0.0049 & 0.049 & 6.2 & 3.9 & Bal. \\
\hline
\end{tabular}




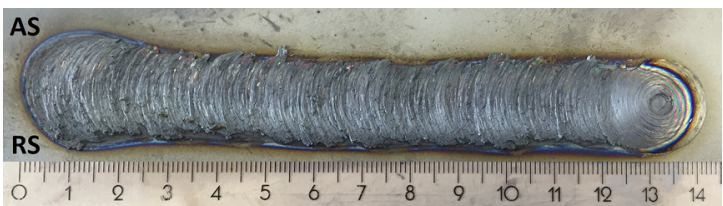

Figure 2. Typical appearance of Titanium Grade 1 deposit with $4000 \mathrm{rpm}$

spaced ripples, which is an inherent characteristic of the FS process. According to Chandrasekharan et al..$^{14}$, there exists a certain time gap between successive material transfer events from the consumable rod to the substrate, while the substrate keeps moving along the deposition direction continuously. The roughness of the coating surface is then determined by the frequency of material transfer in layers. All Titanium Grade 1 deposits were oxidized, with thick oxide layers of grey color.

From a visual inspection of the deposits it could be easily seen that the depositions with higher rotational (3000 and $4000 \mathrm{rpm}$ ) speeds presented more homogeneous surfaces for the complete coatings. Coatings produced at higher rotational speeds were smoother compared to those produced at lower rotational speeds, due to the increased frequency of material transfer. Flash formation at the coating has only been observed in the study performed by Fitseva et al $^{1}$ for the deposition of Ti-6Al-4V onto a Ti-6Al-4V substrate, due to the wide range of rotational speeds available by the FS equipment employed. There, under certain conditions the flash was deposited along the RS of the coating leaving the rod tip almost without flash.

In this study, for the deposition of Titanium Grade 1, the lowest rotational speed $(2000 \mathrm{rpm})$ resulted in a coating with an inhomogeneous layer appearance, with a large amount of material being deposited along the RS and leaving the AS with almost no material deposited (Figure 3). In spite of this tendency for material accumulation at the RS, for these experiments the flash was always formed at the consumable rod, ascending around the tip and giving the rod a mushroomshaped geometry, as described in the literature ${ }^{7}$. In contrast, coatings produced with higher rotational (3000 and $4000 \mathrm{rpm}$ ) speeds presented a homogeneous coating thickness at both sides (AS and RS), as can be seen in Figure 4. Then, it can be expected that when reducing the rotational speed below $2000 \mathrm{rpm}$, flash formation at the RS of the coatings may arise.
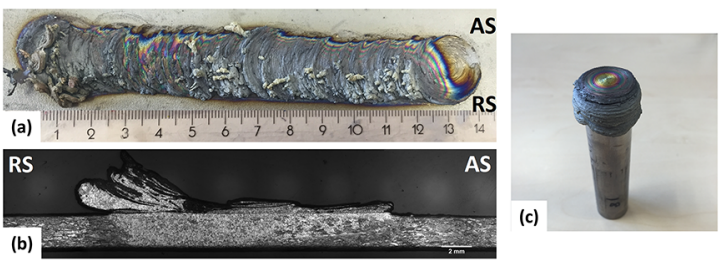

Figure 3. a) Surface appearance of the coating with inhomogeneous layer, b) corresponding cross section and c) consumable rod tip (2000 rpm)

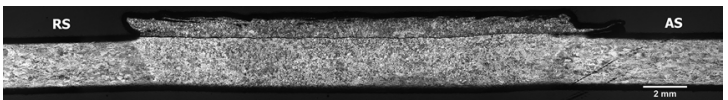

Figure 4. Cross section macrograph of a Titanium Grade 1 deposit onto a Ti-6Al-4V substrate (4000 rpm)

\subsection{Coating Geometry}

The study of the main process parameters is very important due to their influence on the coating geometry and, consequently, its quality ${ }^{9,15}$. In order to verify the influence of the rotational speed, the deposition speed and rod consumption rate were kept constant while varying the rotational speed of the consumable rod. It could be noted that by increasing the rotational speed it led to higher forces and lower torques applied by the machine. Fitseva et al. ${ }^{6}$ stated that from a given rotational speed, higher values do not influence considerably in increasing the temperature of the process, therefore the increase in axial force for higher rotational speed can be considered as a consequence of the high strain applied by unit of distance. On the other hand, the torque decays slowly since the plastified material reaches a condition of low viscosity, due to the low strain rates, limiting the heat generation and promoting a steady state of temperature.

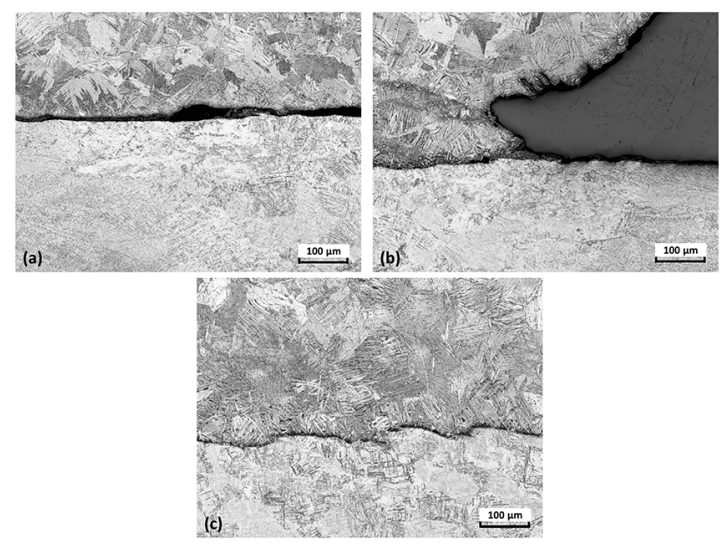

Figure 5. The coating presented (a) a lack of bonding on the AS, (b) no unbonded region on RS and (c) good bonding integrity away from the edges of the coating (4000 rpm)

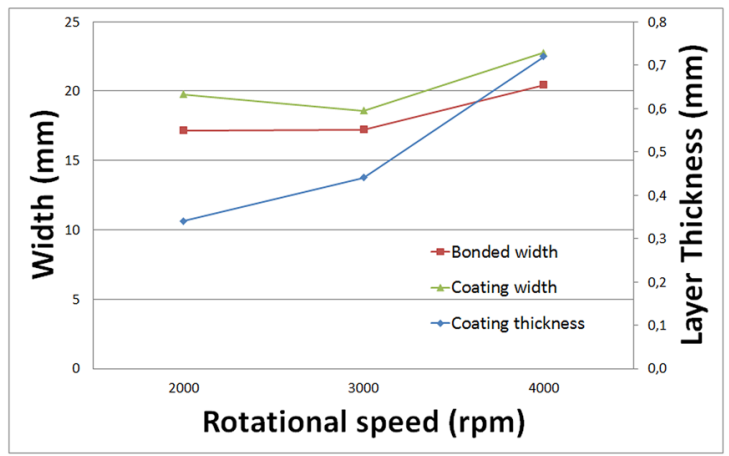

Figure 6. The effects of the rotational speed on the coating thickness and on the bonded and unbonded coating widths 

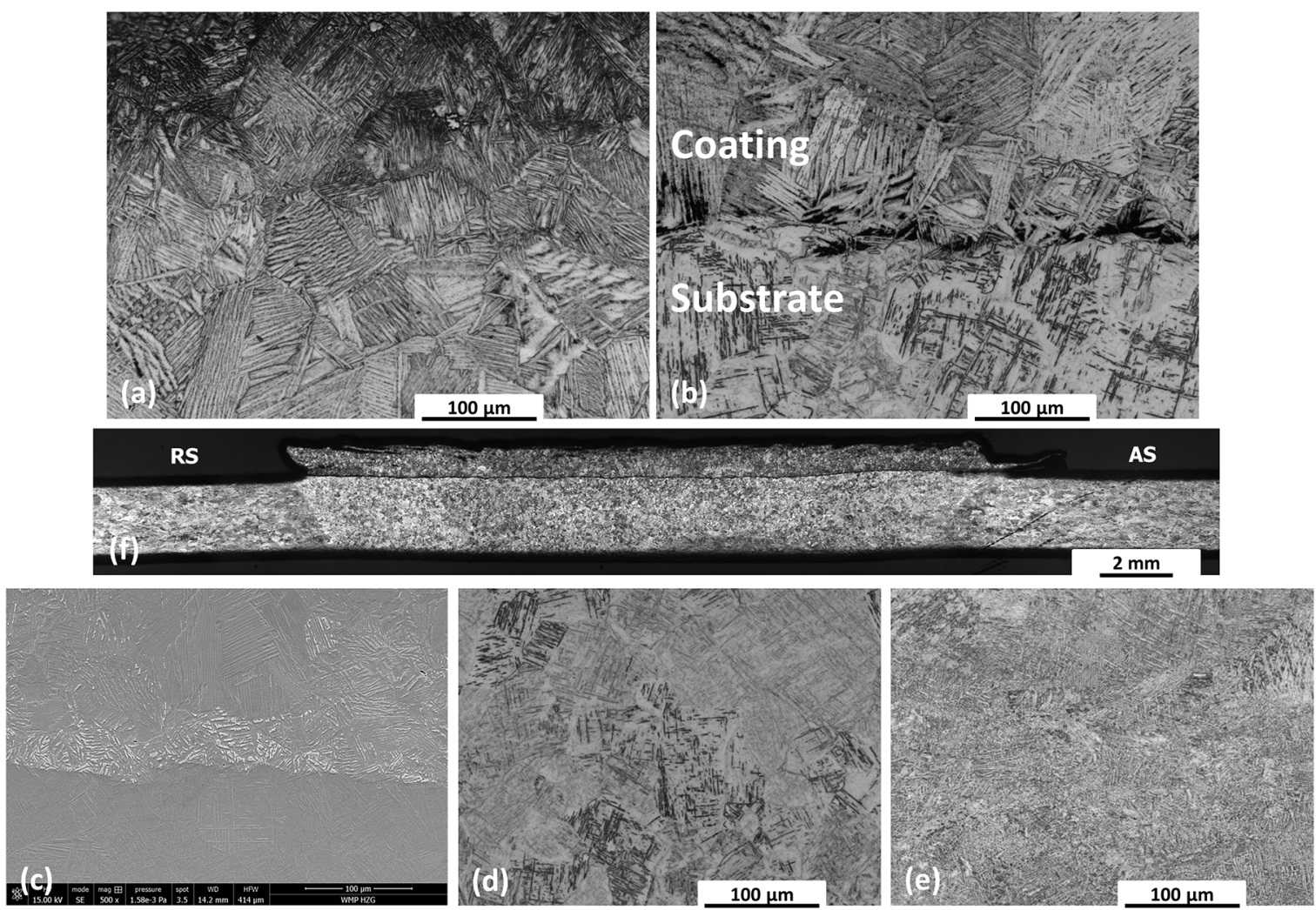

Figure 7. Gradual microstructure transformations on the (a) coating, (b) interface, (c) interface obtained by SEM, (d) substrate heat affected zone, (e) substrate base material and (f) cross section macrograph of the coating (4000 rpm)

The layer geometry was investigated by cross section macrographs on coatings generated with different rotational speeds. A macrograph for the deposition of Titanium Grade 1 onto a Ti-6Al-4V substrate is shown in Figure 4.

The coatings generated in the current study showed a tendency for forming an unbonded region only on the AS of the coatings (Figure 5 (a)), resulting in a good bonding integrity on the RS, as it can be seen in Figure 5(b). The lack of bonding is a result of the inhomogeneous pressure distribution between the center and the edges of the rod. Generally, the width of this unbonded region on either side is less than $10 \%$ of the coating width ${ }^{9}$. This tendency applies to the Titanium Grade 1 coatings, except for the deposition with $2000 \mathrm{rpm}$, in which the unbonded region corresponded to about $13 \%$ of the coating width. Away from the deposit edges, the coating was found to be well bonded to the substrate (Figure $5(\mathrm{c})$ ), therefore the forces applied were sufficient to ensure a good bonding integrity.

The effect of the rotational speed on the coating thickness, the total coating width and the bonded width is presented in Figure 6. The results show that coating thickness is more sensitive to rotational speed than the coating width. Although in some studies ${ }^{8,9,15}$ it was concluded that the coating thickness and width decreased with increasing the rotational speed, it can be observed in Figure 6 that for the deposition of
Titanium Grade 1 an increase in the rotational speed leads to larger coating thicknesses and wider coating widths. This may be related to the fact that in most studies the rod is fed into the process at a constant axial force, while in the current study it was fed in at a constant speed (consumption rate control mode). Therefore, always the same amount of material is fed in, independent of its plastic deformation behavior. It can be assumed that at low rotational speed, the Titanium Grade 1 is not sufficiently plasticized, resulting in thin, inhomogeneous coatings. At higher rotational speeds, more softened material is available, and wider, thicker and smoother coatings are deposited. In Fitseva's work ${ }^{1}$ also the consumption rate control mode was used. There, also an increase in the coating thickness with enhancing the rotational speed was found, although it produced narrower coating widths.

\subsection{Microstructural analysis}

The gradual microstructure transformations through the coating thickness and in the substrate for the deposition of Titanium Grade 1 onto a Ti-6Al-4V substrate can be seen in Figure 7 . The heat generated during the deposition process is mainly lost by conduction to the substrate therefore a heat affected zone is formed. For higher rotational speeds, the substrate was completely heat affected. For the condition of 
$2000 \mathrm{rpm}$ (see Figure 3), the advancing side of the substrate was not completely heat affected, due to the low thickness of deposition in this edge.

Titanium Grade 1 is unalloyed titanium, which undergoes an allotropic phase transition. Its close-packed hexagonal structure ( $\alpha$ phase) changes to a body-centered cubic structure $\left(\beta\right.$-phase) at $885^{\circ} \mathrm{C}\left(1625^{\circ} \mathrm{F}\right)$, and this structure persists at temperatures up to the melting point ${ }^{6}$. During cooling, the backward transformation results in lamellar $\alpha$ plates, as can be seen in the coating in Figure 7 (a). The microstructure changes indicate that in all experiments the process temperature exceeded the $\beta$-transus temperature, and after cooling only $\alpha$ phase can be found by OM in the coating microstructure, which has formed within the previous $\beta$ grains. Figure 7 (b) shows the interface between the coating and the heat affected substrate. By OM it seems to present voids in the interface, although SEM confirmed that the coating is completely bonded to the substrate, with no porosities (Figure 7(c)). Figure 7 (d) shows the heat affected zone of the substrate, which corresponded to its complete thickness and (e) the substrate base material microstructure (Ti-6Al-4V).

\section{Conclusions}

The results obtained during this study showed the feasibility and properties for the deposition of Titanium Grade 1 onto a Ti-6Al-4V substrate by FS for different rotational speeds.

- The coatings were found to be continuous with homogeneous surface appearance and free of voids in the bonding interface for the depositions with rotational speeds of 3000 and $4000 \mathrm{rpm}$.

- Inhomogeneous coatings with $2000 \mathrm{rpm}$ rotational speed were due to an insufficient amount of plasticized material.

- The coatings' surfaces were oxidized, and the use of protective gas may be required for future technical applications.

- Only the AS of the coatings presented unbonded edges, with good bonding integrity along the coating and on the RS.

- The coating geometry was found to be dependent on the rotational speed: an increase in the rotational speed led to wider and thicker coatings.

- High rotational speeds imply incompletely heat affected substrates. The lowest rotational speed of $2000 \mathrm{rpm}$ was not completely heat affected on the advancing side, due to the low amount of material deposited on this edge.

- The microstructure of the coatings indicated that Titanium Grade 1 has exceeded the $\beta$-transus temperature and was deformed in the $\beta$-phase.

\section{Acknowledgments}

The authors would like to acknowledge the UFPE laboratory (COMPOLAB), CNPQ and the Joining Technology Group of the german institute $\mathrm{HZG}$, for giving financial support and all the conditions to carry out this work.

\section{References}

1. Fitseva V, Krohn H, Hanke S, dos Santos JF. Friction surfacing of Ti-6Al-4V: Process characteristics and deposition behaviour at various rotational speeds. Surface and Coatings Technology. 2015;278:56-63

2. Rao KP, Damodaram R, Rafi HK, Ram GDJ, Reddy GM, Nagalakshmi R. Friction surfaced Stellite 6 coatings. Materials Characterization. 2012;70:111-116.

3. Klopstock H, Neelands AR, assignees. An improved method of joining or welding metals. United Kingdom patent GB 572789. 1945 Oct 24.

4. Gandra J, Krohn H, Miranda RM, Vilaça P, Quintino L, dos Santos JF. Friction surfacing-a review. Journal of Materials Processing Technology. 2014;214(5):1062-1093.

5. Vitanov VI, Javaid N, Stephenson DJ. Application of response surface methodology for the optimisation of micro friction surfacing process. Surface and Coatings Technology. 2010;204(2122):3501-3508.

6. Fitseva V, Hanke S, dos Santos JF, Stemmer P, Gleising B. The role of process temperature and rotational speed in the microstructure evolution of Ti-6Al-4V friction surfacing coatings. Materials \& Design. 2016;110:112-123.

7. Hanke S. Microstructural Alterations of Commercial Metallic Alloys by Friction Surfacing. [Thesis]. Essen: University of Duisburg-Essen; 2014.

8. Gonçalves M. Caracterização Mecano Tribológica e Comportamento em Corrosão de Revestimentos Depositados por Atrito. [Dissertation]. Vitória: Universidade Federal do Espírito Santo; 2010.

9. Rafi HK, Ram GDJ, Phanikumar G, Rao KP. Friction surfaced tool steel (H13) coatings on low carbon steel: A study on the effects of process parameters on coating characteristics and integrity. Surface and Coatings Technology. 2010;205(1):232242.

10. Vitanov VI, Voutchkov II. Process parameters selection for friction surfacing applications using intelligent decision support. Journal of Materials Processing Technology. 2005;159(1):2732 .

11. Rafi HK, Ram GDJ, Phanikumar G, Rao KP. Friction Surfacing of Austenitic Stainless Steel on Low Carbon Steel: Studies on the Effects of Traverse Speed. In: Proceedings of the World Congress on Engineering (WCE); 2010 Jun 30-Jul 2; London, United Kingdom. 
12. Rafi HK, Ram GDJ, Phanikumar G, Rao KP. Microstructural evolution during friction surfacing of tool steel H13. Materials \& Design. 2011;32(1):82-87.

13. Hanke S, Beyer M, Silvonen A, dos Santos JF, Fischer A. Cavitation erosion of $\mathrm{Cr} 60 \mathrm{Ni} 40$ coatings generated by friction surfacing. Wear. 2013;301(1-2):415-423.

14. Chandrasekaran M, Batchelor AW, Jana S. Friction surfacing of metal coatings on steel and aluminum substrate. Journal of Materials Processing Technology. 1997;72(3):446-452.

15. Gandra J, Pereira D, Miranda RM, Vilaça P. Influence of Process Parameters in the Friction Surfacing of AA 6082-T6 over AA 2024-T3. Procedia CIRP. 2013;7:341-346.
16. Gandra J, Miranda RM, Vilaça P. Performance analysis of friction surfacing. Journal of Materials Processing Technology. 2012;212(8):1676-1686.

17. Rao KP, Sankar A, Rafi HK, Ram GDJ, Reddy GM. Friction surfacing on nonferrous substrates: a feasibility study. International Journal of Advanced Manufacturing Technology. 2013;65(58):755-762.

18. ASTM International. ASTM E3-01 - Standard Practice for Preparation of Metallographic Specimen. West Conshohocken: ASTM International; 2007. 